\title{
Double-wire-guided reopenable-clip closure of a mucosal defect after endoscopic papillectomy
}

Endoscopic papillectomy has been reported as a curative endoscopic treatment for laterally spreading tumors of the duodenal papilla and near the papilla $[1,2]$. However, endoscopic papillectomy is associated with postoperative complications such as pancreatitis, cholangiopancreatic stricture, and bleeding. Insertion of a pancreatic ductal stent may prevent these problems and should be performed if possible $[3,4]$. In addition, clip closure of mucosal defects may reduce delayed bleeding [5]. However, the presence of pancreatic and bile duct stents may interfere with clip closure and result in incomplete closure of the mucosal defects. We developed a new method, double-wire-guided closure with reopenable clips, which enables closure of mucosal defects before pancreatic and bile duct stents are inserted. With this method, guidewires are inserted into the pancreatic and bile ducts after complete resection of the lesion. The mucosal defect is then securely closed using a reopenable clip (SureClip; Micro-
Tech Co., Ltd, Nanjing, China), with two guidewires in place to prevent respiratory movement. The clip can be opened and closed even with the elevator mechanism of conventional duodenoscopes.

Our patient was a 65-year-old man with a laterally spreading tumor in the descending duodenum extending to the papilla. We performed piecemeal resection of the tumor with a duodenoscope (TJF290V; Olympus Medical Systems). We closed the mucosal defect using double-
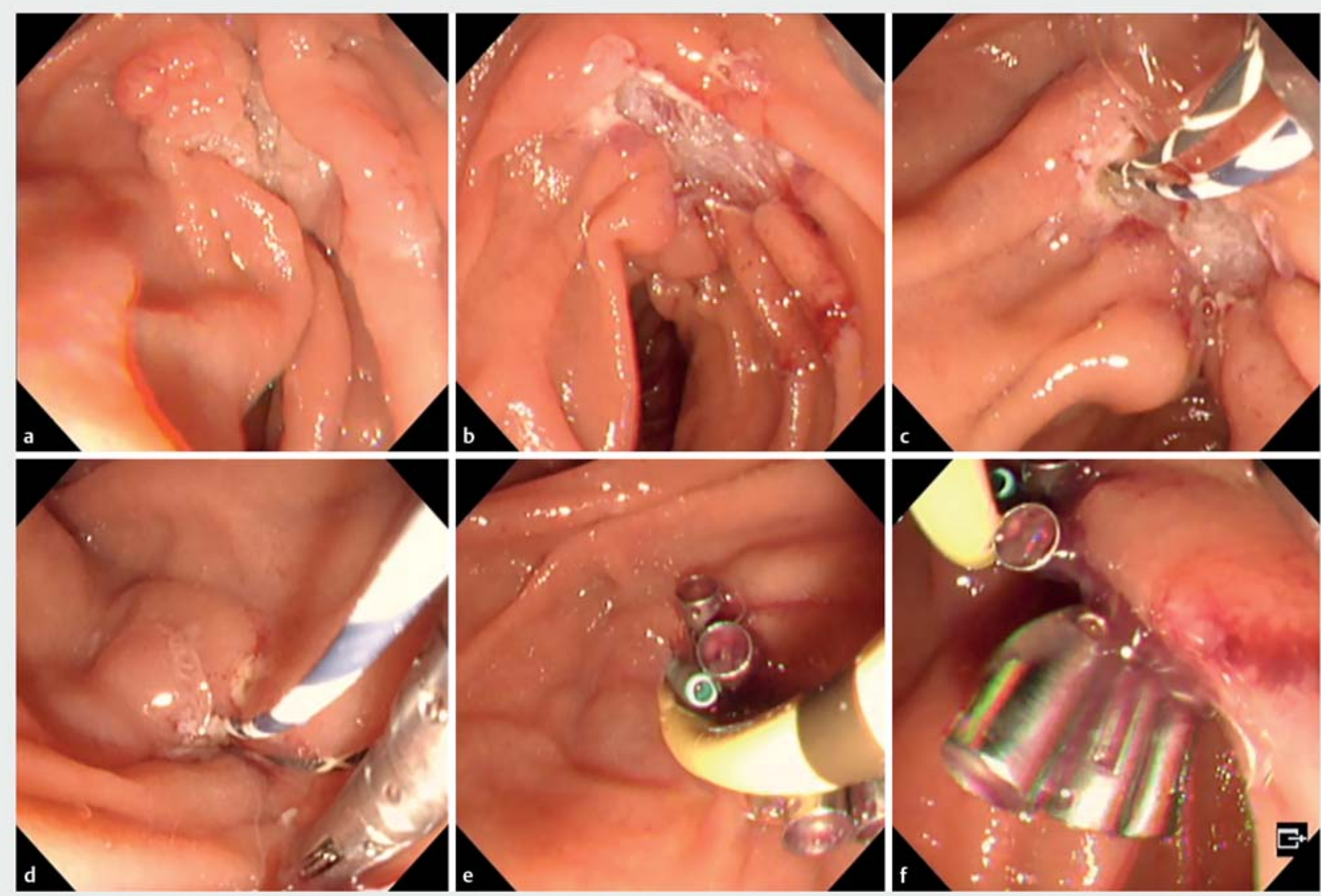

- Fig. 1 a Laterally spreading tumor $20 \mathrm{~mm}$ in size in the descending duodenum extending to the papilla in a 65 -year-old man. b Mucosal defect after piecemeal resection by endoscopic papillectomy using a duodenoscope. c Guidewires cannulated into the pancreatic duct and bile duct. d Normal mucosa at the edge of the mucosal defect completely grasped and held by a reopenable clip using the double-wire-guided reopenable-clip closure method. e Plastic stents inserted into the pancreatic duct and bile duct. $\mathbf{f}$ Complete closure of the mucosal defect after endoscopic papillectomy. 


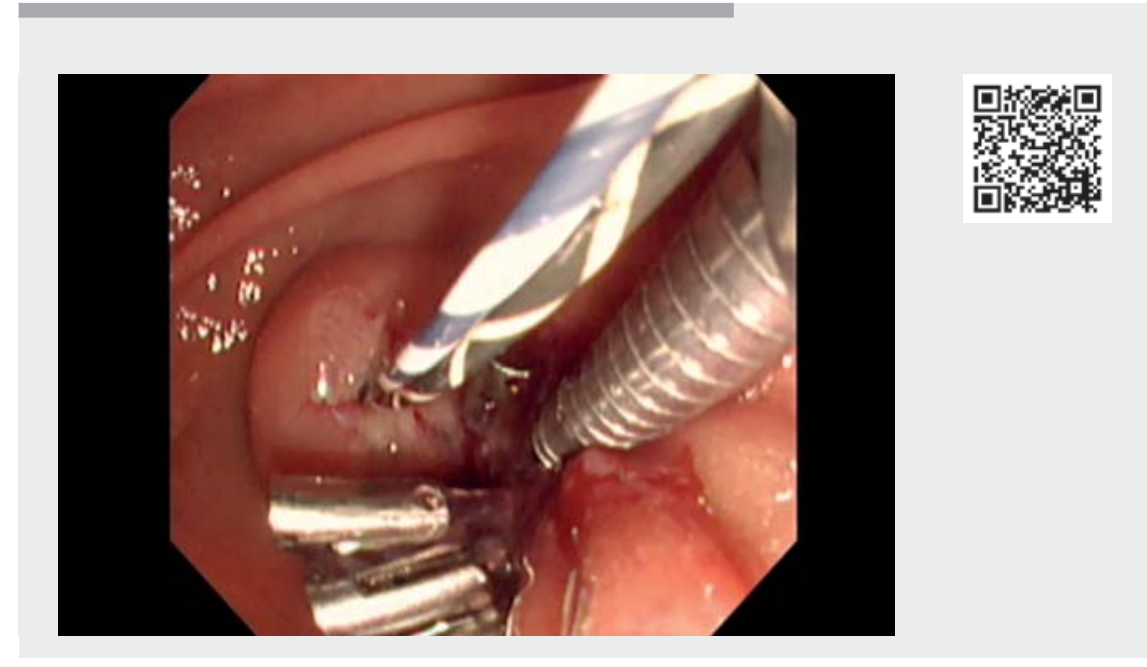

$\checkmark$ Video 1 Double-wire-guided reopenable-clip closure of a mucosal defect after endoscopic papillectomy.

wire-guided closure with a reopenable clip. If the reopenable clip inadvertently gripped the ulcer base of the mucosal defect, it could be reopened and reclosed to completely close the defect on both sides. Since two wires were intubated into the pancreatic and bile ducts, respiratory movement was prevented, and the reopenable clip could be easily positioned. Subsequently, pancreatic and bile duct stents were inserted. The mucosal defect was completely closed ( $\vee$ Fig. 1, \Video 1). The patient was discharged without any adverse events.

Double-wire-guided closure with reopenable clips can reliably close the mucosal defect after endoscopic papillectomy before pancreatic and bile duct stents are inserted.

\section{Endoscopy_UCTN_Code_TTT_1AR_2AK}

\section{Competing interests}

The authors declare that they have no conflict of interest.
The authors

Tatsuma Nomura ${ }^{1,2} \odot$, Shinya Sugimoto ${ }^{2}$, Toji Murabayashi $^{2}{ }^{\odot}$, Jun Oyamada ${ }^{2}$, Keiichi Ito ${ }^{1}$, Akira Kamei ${ }^{2}$

1 Department of Gastroenterology, Mie Prefectural Shima Hospital, Shima, Mie, Japan

2 Department of Gastroenterology, Ise Red Cross Hospital, Ise, Mie, Japan

Corresponding author

\section{Tatsuma Nomura, MD}

Department of Gastroenterology, Mie Prefectural Shima Hospital, 1257 Ugata, Ago, Shima, Mie 517-0595, Japan m06076tn@icloud.com

\section{References}

[1] Klein A, Tutticci N, Bourke M]. Endoscopic resection of advanced and laterally spreading duodenal papillary tumors. Dig Endosc 2016; 28: 121-130

[2] Klein A, Qi Z, Bahin FF et al. Outcomes after endoscopic resection of large laterally spreading lesions of the papilla and conventional ampullary adenomas are equivalent. Endoscopy 2018; 50: 972-983

[3] Harewood GC, Pochron NL, Gostout C]. Prospective, randomized, controlled trial of prophylactic pancreatic stent placement for endoscopic snare excision of the duodenal ampulla. Gastrointest Endosc 2005; 62: 367-370

[4] Wang Y, Qi M, Hao Y et al. The efficacy of prophylactic pancreatic stents against complications of post-endoscopic papillectomy or endoscopic ampullectomy: a systematic review and meta-analysis. Therap Adv Gastroenterol 2019. doi:10.1177| 1756284819855342

[5] Kagawa K, Kubota K, Kurita Y et al. Effect of preventive closure of the frenulum after endoscopic papillectomy: a prospective pilot study. J Gastroenterol Hepatol 2020; 35: $374-379$

Bibliography

Endoscopy 2022; 54: E141-E142

DOI 10.1055/a-1408-1572

ISSN 0013-726X

published online 16.4.2021

(c) 2021. Thieme. All rights reserved. Georg Thieme Verlag KG, Rüdigerstraße 14, 70469 Stuttgart, Germany

\section{ENDOSCOPY E-VIDEOS \\ https://eref.thieme.de/e-videos}

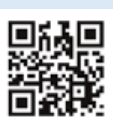

Endoscopy E-Videos is an open access online section, reporting on interesting cases and new techniques in gastroenterological endoscopy. All papers include a high quality video and all contributions are freely accessible online. Processing charges apply (currently EUR 375), discounts and wavers acc. to HINARI are available.

This section has its own submission website at

https://mc.manuscriptcentral.com/e-videos 